\title{
Cuatro formas de construir un predicador en América. Notas para un estudio sobre las conexiones entre predicación barroca y discurso criollo en el siglo XVII
}

\author{
Four ways of creating a preacher in the New World. Notes towards a study of \\ criollo discourse and preaching in XVII Century Latin America
}

Juan Vitulli

jvitulli@nd.edu

University of Notre Dame, Estados Unidos

Recepción: 15 Abril 2021

Aprobación: 08 Agosto 2021

Publicación: 01 Noviembre 2021

Cita sugerida: Vitulli, J. (2021). Cuatro formas de construir un predicador en América. Notas para un estudio sobre las conexiones entre predicación barroca y discurso criollo en el siglo XVII. Orbis Tertius, 26(34), e218. https://doi.org/10.24215/18517811e218

\begin{abstract}
Resumen: En las siguientes páginas, realizo un recorrido cronológico a través de las obras de cuatro letrados representativos que, de manera implícita y explícita, proponen posibles imágenes para pensar la figura del predicador criollo en el siglo XVII. Estos aportes discursivos provienen de temporalidades y espacios heterogéneos, destacando el grado de complejidad y diversidad que se puede hallar en la forma en que distintos escritores postularon una imagen posible del nuevo predicador americano.

Palabras clave: Predicador Americano, Discurso Criollo, Barroco, Estudios Coloniales.

Abstract: In this article I make a chronological journey through the works of four representative Creole men of letters who, in an implicit and explicit way, propose possible images to think about the Creole preacher's figure in the seventeenth century. These discursive contributions come from heterogeneous temporalities and spaces, highlighting the degree of complexity and diversity that can be found in the way in which different writers postulated a possible image of the new American preacher.
\end{abstract}

Keywords: American Preacher, Creole discourse, Barroco, Colonial Studies.

En las últimas décadas, los estudios enfocados en la cultura americana virreinal han ampliado su campo de trabajo y su zona de influencia. Lejos ya de ser entendida como una disciplina abocada a la exploración de un pasado concebido como pieza de anticuario - que poco o nada tiene que ver con nuestro presente- los estudios coloniales han permitido observar una serie de continuidades y rupturas culturales que operaron desde los tiempos virreinales y que aún merecen ser investigadas. A partir de la revalorización de este complejo campo cultural, ha sido posible localizar toda una serie de cruces discursivos que fomentan un entendimiento mayor de unos de los períodos más importantes en la historia continental. El archivo colonial latinoamericano se concibe, así, como un territorio elástico, en pugna, en constante transformación y redefinición donde, tanto en el pasado colonial como en la contemporaneidad, diferentes intervenciones letradas han venido trazando un diálogo inconcluso, en proceso y fructífero. 
Dentro de una visión acotada de esta amplia y heterogénea serie discursiva, el siglo XVII presenta un momento singular y distintivo donde indagar las transformaciones de este archivo. Debido a estas nuevas miradas sobre el hecho colonial, es posible observar un interés creciente por diferentes producciones letradas que se originan pero que a la vez exceden el estudio de los géneros literarios tradicionalmente estudiados -crónicas, poesía, teatro, narrativa. Al analizar la producción cultural de este dinámico período, resulta indispensable recuperar distintas expresiones que formaron parte del heterogéneo campo colonial. La predicación sagrada, por ejemplo, se presenta como una de las producciones letradas con mayor presencia a lo largo de todo el siglo XVII. Heredera de las directivas y cambios propuestos a partir del Concilio de Trento, este tipo de producción contiene innumerables aristas desde donde poder abordarla. Los estudios generales sobre el fenómeno de la predicación barroca (Smith, 1978; Cerdan, 1985 y 2002; Herrero Salgado, 1986; De la Flor, 1995) han sólidamente establecido que la oratoria sagrada requiere ser estudiada desde una perspectiva interdisciplinaria ya que en ella se perciben intersecciones múltiples tanto con discursividades rectoras del pensamiento Barroco (lo teológico, lo político, lo artístico, lo social) como así también es posible recuperar diferentes significantes culturales decisivos al momento de pensar la heterogénea cultura barroca americana. Con esto último, me refiero tanto a la palabra (oral y escrita), la imagen (esculturas, relieves y pinturas), el sonido (la acústica), el cuerpo (las políticas de las acciones y los gestos), el espacio y el rol del predicador que se ponen en juego al reflexionar sobre la predicación y sus funciones.

Curiosamente, la oratoria sagrada virreinal no ha sido explorada por la crítica académica más allá de sus límites textuales. De esta manera se ha privilegiado una aproximación de tono descriptivo/estructural cuya teleología reside en la posibilidad de clasificar, catalogar y enumerar autores, textos y estilos en pugna alrededor de este fenómeno cultural poliédrico. Como consecuencia, este parcial acercamiento no ha indagado en un tipo de análisis que destaque las intersecciones culturales entre la predicación (como práctica cultural compleja) y su horizonte de representación, aislando el fenómeno de la oratoria y creando una imagen falsa de la misma sin interesarse en conectarla con otras discursividades presentes en la ciudad letrada virreinal. Para evitar esta trampa hermenéutica, en mi ensayo realizo una breve exploración en torno a cuatro manuales de predicación escritos en territorios virreinales americanos por autores que formaron parte de la experiencia colonial. En cada uno de los casos que aquí voy a analizar, nos encontramos con predicadores que deciden publicar un arte de sermones desde su singular espacio enunciativo colonial. Estos manuales responden desde sus particulares contextos de producción a la pregunta rectora de este ensayo: ¿cómo imaginar y crear al perfecto predicador desde el "Nuevo Mundo"? En las siguientes páginas, realizo un recorrido cronológico a través de las obras de cuatro letrados representativos que, de manera implícita y explícita, proponen posibles imágenes para pensar la figura del predicador criollo en el siglo XVII. Como voy a demostrar, estos aportes discursivos provienen de temporalidades y espacios heterogéneos, destacando el grado de complejidad y diversidad que se puede hallar en la forma en que distintos escritores postularon una imagen posible del nuevo predicador americano. Cada uno de los tratados aquí presentados imagina y construye una versión discursiva de una inédita figura (la del predicador ejerciendo su tarea en un espacio y una sociedad alternativos) que pueden conectarse con los significantes más destacados que forman parte del discurso criollo. Cada uno de estos predicadores que he seleccionado ha vivido en diferentes ciudades de los virreinatos americanos y, a su vez, ha producido un texto que contiene ciertas gestualidades discursivas que forjan una idea posible del predicador criollo. Con esta exploración de las figuraciones retóricas utilizadas para pensar la naturaleza del predicador americano, trataré de demostrar cómo este proceso conjunto, contradictorio, heterogéneo, y polifónico que hoy conocemos como la creación de una mirada criolla se construyó a partir de posiciones enunciativas múltiples, inestables y que, ya desde la primera mitad del siglo XVII, esta intersección cultural aparece marcada por la fluidez, la transitoriedad, en una construcción colectiva donde participaron voces de diverso origen y circunstancia.

Las distintas intervenciones letradas sobre la oratoria que presentaré a continuación serán buen ejemplo para indagar los alcances y los límites de este orden, y al mismo tiempo permitirán establecer un recorrido 
de lectura de tipo arqueológico donde conectar cuatro imágenes posibles de la figura del predicador criollo. La primera pregunta que se impone para suplementar la propuesta anteriormente descripta debe enfocarse sobre la posibilidad de existencia de la figura del predicador criollo; es decir, es preciso interrogarse acerca de la presencia de manuales de predicación escritos en los territorios americanos que se concentraron en crear diferentes dispositivos textuales y buscaron incorporar el particular espacio de la enunciación criolla dentro del tema más amplio de la oratoria barroca y la creación del sujeto de la prédica.

\section{JuAN Rodríguez de León. El PREdicador INCANSABle}

Juan Rodríguez de León (Lisboa 1590-Puebla 1644) es, quizás, el menos conocido de tres hermanos que dejaron una marca indeleble en el mundo virreinal hispanoamericano. Su padre, Diego López de León era hijo de un judío portugués que fue quemado vivo en Lisboa. Como consecuencia de este peligroso ambiente, comenzó un solitario peregrinar que incluyó desplazamientos dentro y fuera de la península ibérica: de Lisboa hacia Valladolid, dejando allí a su familia (esposa e hijos) para luego cruzar el Atlántico y afincarse en Buenos Aires, lugar donde logra cierta estabilidad económica como comerciante. En 1605, ya en el territorio austral, López de León puede reencontrarse con su familia conformada por su esposa Catalina de Esperanza Pinedo y dos hijos varones, Juan y Antonio, que se le unirán en esta nueva etapa de su vida. En tierras americanas nacerá el tercer hijo, que será bautizado como Diego. Los hijos de López de León seguirán la trayectoria ascendente de su padre en los territorios americanos y podrán acceder a diferentes instituciones educativas que los formarán intelectualmente. Antonio y Diego de León Pinelo difícilmente necesiten una presentación biográfica ya que sus figuras y sus obras son reconocidas por la crítica académica: el primero es conocido como recopilador de leyes de Indias, relator del consejo y escritor incansable; mientras que su hermano menor Diego ha pasado a la posteridad, entre otras cosas por su labor como jurista y rector de la Universidad Mayor de Lima. El mayor de los hermanos, Juan (que nunca adoptó el apellido como sus hermanos) continúa siendo casi un desconocido. Gracias a los trabajos de Ernesto de la Torre Villar (1996), se ha podido reconstruir una vida itinerante que cruza los territorios materiales y simbólicos de Lisboa, Valladolid, Buenos Aires, Córdoba, Tucumán, La Plata, Lima, Madrid y Puebla de los Ángeles; al mismo tiempo se ha vuelto visible una labor intelectual que nada tiene que envidiar a la de sus reconocidos hermanos. Juan Rodríguez de León se destacó como orador sagrado y de su producción conocemos hoy aproximadamente treinta piezas oratorias de importancia de entre las que se destaca una oración fúnebre dedicada a Fray Hortensio Félix Paravicino. Dejó su marca también como prologuista del Epitome de la Biblioteca Oriental y Occidental (1629) y del Tratado de confirmaciones reales (1630), ambas escritas por su hermano Antonio. También fue invitado por el famoso obispo de Puebla Juan de Palafox y Mendoza para escribir una nota prologal a su Historia real sagrada del Obispo (1643). Fue en Puebla que escribió su obra mayor, El predicador de las gentes San Pablo. Ciencia, avisos y obligaciones de los predicadores evangélicos, que será publicada en Madrid en 1638. Este impreso es el que me interesa apenas describir en este ensayo ya que es un tratado sobre la predicación basado en la figura del apóstol san Pablo como ejemplo máximo del orador cristiano que el autor escribió en territorio mexicano y que, posiblemente, sea el primero de la serie de artes de predicación americanos. En su libro, Rodríguez de León no sigue la ya codificada estructura argumental de los tratados de retórica adaptados a lo divino, sino que prefiere alcanzar el mismo objetivo (describir las características fundamentales del predicador ideal) a través de diferentes capítulos donde se combinan episodios de la vida de san Pablo que pueden interpretarse a través de una glosa que traduce las acciones dentro del marco de la predicación. A diferencia de muchos de los tratados de mayor circulación de la época, donde la figura del predicador surge a partir de diferentes secciones y capítulos basados (pero no exclusivamente) en la estructura de los libros de retórica clásica, de León construye una imagen del predicador a partir de materiales diversos, asentando su propósito a través de la idea del modelo/antecedente que, aunque inimitable en su perfección, dejará el camino y el recorrido que los demás predicadores deberán proseguir. Curiosamente, siendo el primer tratado de esta serie 
de artes de predicar escritos en territorio americano, Rodríguez de León no hace ninguna referencia a su propio espacio de enunciación ni a su inédita producción discursiva desde la geografía virreinal. A pesar de esta ausencia de referencias explícitas a su situación inédita como predicador en los territorios americanos, Rodríguez de León va a proponer, de manera oblicua, una forma de acercarse a la figura del predicador que, tácitamente, contiene su propia experiencia como sujeto en tránsito por la geografía imperial. En los más de doscientos cincuenta y cinco folios que su obra ocupa, el tratadista sostiene que -más allá de los saberes y disciplinas que es necesario aprender y practicar para alcanzar la calidad oratoria- una de las cualidades mayores en la construcción del perfecto predicador está vinculada con el movimiento y el desplazamiento a través de diferentes territorios. Para Rodríguez de León, la figura de san Pablo es crucial ya que "tanto alumbró predicando, tanto vio discurriendo, que el sol, por su elíptica de oro, dando vuelta al mundo sin cansarse y comunicando luz sin detenerse, pareció su retrato en los viajes, o su púlpito en los sermones." (1638, p. 51). El sol y su incesante movilidad se vuelven, a partir de esta analogía, figuras que permitirán interpretar plenamente la función del predicador en el Barroco ya que san Pablo será el modelo a seguir por las futuras generaciones. La luz se entiende aquí como la doctrina que necesariamente estará también asociada con la praxis del predicador, esto es con la capacidad de "dar vuelta al mundo sin cansarse" (1638, p. 51) trasmitiendo su palabra, pero simultáneamente adquiriendo una distinción inédita debido al derrotero por tierras extrañas. No hay, parecería sugerir Rodríguez de León, separación entre el conocimiento adquirido y el espacio de enunciación que se asume en cada acto del saber, y así invierte la relación sol/modelo, llamando al primero retrato tanto de la incansable movilidad del segundo, pero también imagen de su propio espacio material desde donde se lleva a cabo la prédica, el púlpito.

Al plantear esta poética del desplazamiento como base de la formación intelectual del predicador, Rodríguez de León abre el camino para las futuras generaciones de predicadores que podrán incorporar en sus artes de predicación referencias al carácter excéntrico de su palabra. En el capítulo XXIV del Libro uno Rodríguez de León plantea la necesidad de describir las peregrinaciones realizadas por san Pablo durante su vida y así establecer un vínculo entre sus viajes y su capacidad oratoria. Específicamente, el religioso afirma que el lector del tratado (el predicador contemporáneo que él está buscando formar) podrá observar cómo la "ciencia del púlpito se aumenta con las noticias de las tierras" ya que una de las facetas más importantes de la figura del orador católico solo puede debidamente modelarse a través del desarrollo de una cualidad “experimental” (1638, p. 50). Esta característica introducida en la sección se irá desarrollando a medida que el capítulo avance, representando a un predicador que deberá adaptar su arte libresco a los nuevos escenarios con los que irá encontrándose ya que es sumamente importante educarse "caminando varias tierras para saber diversas costumbres, no fiando solo a la lición la sabiduría, sino a los ojos de la verdad” (1638, p. 51). Más adelante, de León interpreta las constantes peregrinaciones del apóstol en clave pedagógica y establece un marco discursivo que apela al conocimiento y al desplazamiento como bases para fundar al predicador desde y para América ya que, si san Pablo "había de enseñar bien, era que caminase, porque aprendiendo varias costumbres, acertaría a conocer diversas inclinaciones" (1638, p. 51). Este predicador señala así la necesidad de crear un modelo de predicador que base su potencial en una idea mucho más fluida de su labor que ponga en primer plano la experiencia y la praxis. El tratadista finaliza su defensa del saber experimental a partir de una afirmación de carácter claramente aforística donde asevera que "saber mucho habiendo andado poco, parece difícil, aunque es posible; pero si a la Ciencia aprendida se juntare la experimentada, conoceráse el aumento con importancia, y hallaráse el provecho sin trabajo" (1638, p. 51).

Este modelo que va desarrollando Rodríguez de León cobrará una dimensión aún mayor cuando afirme una oposición que deberá superarse si se quiere alcanzar la necesaria altura intelectual para poder desempeñar el rol de predicador en este nuevo escenario mundial. Me refiero al contraste entre lo que él llama "ciencia experimentada" y saber libresco. El predicador afirma que "[P] or ser verdad conocida que aprovecha con superioridad la ciencia experimentada y no dejar la patria es carecer de la experiencia. Que la sabiduría no se encarceló en los preceptos, y para excusarse de los caminos" (1638, p. 51). En este sentido, quiero señalar 
tres significantes que serán fundacionales y re-aparecerán en las otras poéticas del predicador criollo que se desarrollarán en la segunda mitad del siglo XVII, me refiero a la conexión entre acumulación del saber movilidad e inestabilidad enunciativa que aparecen en esta cita bajo las ideas de experiencia-, camino y patria. Este conjunto de tres elementos definirá, de manera oblicua pero persistente, las distintas figuraciones del predicador en América y el aporte de Rodríguez de León tiene un peso fundamental ya que fijará los márgenes de una retórica que no cesará de practicarse por más de un siglo y que involucrará siempre el valor distintivo desde lo social de la posesión de un saber, junto a la capacidad de actualizar este conocimiento de acuerdo con el espacio que se habite en ese momento. El conocimiento adquirido en las distintas instituciones educativas no será el único elemento que le permitirá al predicador constituirse en el actor preparado para llevar a cabo su tarea, sino que, también deberá demostrar lo que podría definirse como una sabiduría situacional que deberá poner en juego en cada uno de los espacios que habite. Unos años más adelante, otro sujeto en tránsito llamado Andrés Ferrer de Valdecebro tomará esta poética del desplazamiento y añadirá otro nivel de complejidad como veremos a continuación.

\section{Andrés Ferrer de Valdecebro. Volviendo a ¿CASa?}

Andrés Ferrer de Valdecebro nació en Albarracín (Teruel) en 1620, en el seno de una familia noble cuyo linaje se conectaba con la casa de san Vicente Ferrer. En este contexto fue educado bajo estrictas normas humanísticas hasta que el joven estudiante decidió viajar a Madrid, ingresar en la Orden de Predicadores y luego obtener el grado de Maestro en Sagrada Teología en el convento de Santo Tomás. Los documentos biográficos consultados no contienen información específica de su viaje a Nueva España, pero es posible aseverar que para 1640 Valdecebro ya se encontraba en los territorios virreinales. ${ }^{1}$ En Puebla fue Rector del Real Colegio de San Luis, ejerciendo una tarea pastoral e intelectual notable que puede reconstruirse a partir de la gran cantidad de libros (al menos siete figuran en los catálogos estudiados) que el autor dice haber publicado en su estancia americana. ${ }^{2}$ En 1658, el dominico ya ha regresado a España, y comienza una impactante tarea de escritura y publicación: a partir de esta fecha y hasta el día de su muerte, el predicador publicará dieciséis libros, y al mismo tiempo impartirá clases de Teología Moral en Alcalá de Henares, se vinculará con la Corte, llegando luego a ser Calificador del Consejo de la Suprema Inquisición. Su muerte acaeció en $1680 .{ }^{3}$ Valdecebro orientó su vida y obra hacia la oratoria y los temas religiosos; pero su curiosidad intelectual se aprecia también en una variada y heterogénea producción: tratados de predicación, misceláneas, hagiografías, tratados políticos, sátiras, discursos sobre poesía, tratados teológicos, algunos poemas, libros de emblemas y jeroglíficos constituyen un archivo extremadamente completo que testimonian la importancia de este autor y su participación en la cultura del Barroco. Puebla, Madrid, Alcalá, Valencia, Salamanca y Pamplona constituyen un mapa simbólico, un territorio profuso que informa sobre dónde el autor escribe, publica o hace circular su obra, a veces usando también seudónimos tales como Sanedrio Rifer de Brocaldino o Suplicio Severo cuando su tarea de escritor se dedicaba a la vena crítica, por la cual fue exiliado de la corte. ${ }^{4}$ A su vez, se ha notado que el autor dejó unos nueve manuscritos que su familia se encargó de cuidar. Sin lugar a dudas, sus obras más conocidas (de la cuales se hicieron cuatro impresiones) fueron los dos tomos titulados Govierno general, moral y politico hallado en las fieras y animales silvestres (1658) y su continuación, el Govierno general, moral y politico hallado en las aves más generosas y nobles (1669).

Leyendo el Orador católico (probablemente escrito en 1640, cuando Valdecebro aún residía en Puebla), hallé que la conexión de Valdecebro con el mundo colonial no sólo tenía que ver con el espacio donde vivió, enseño y escribió, sino que también dejó constancia en este libro de su conexión con los letrados criollos mexicanos. En la sección "Al que leyere", Valdecebro presenta un primer recuerdo de la Puebla virreinal:

Lo escribí en la Nueva España, adonde adelanta así la viveza de los ingenios, como el uso de la razón la naturaleza de los Criollos, y con breve enseñanza salen muy aprovechados. No tienen a la vista el premio, y como se hallan en su patria 
extraños, les dura el tesón del estudio, hasta que conocen y experimentan lo que les obliga a aflojar. Fueran admiración al mundo, si los paladeara alguna esperanza de lograr sus desvelos (1658, p. 22).

La primera configuración que Valdecebro hace se conecta con los significantes más visibles en torno a la constitución de un discurso criollo durante el siglo XVII: la capacidad intelectual de este sector sobresale en el paisaje mexicano debido tanto a sus cualidades infusas como a su sorprendente capacidad de aprendizaje. Esta apología del ingenio criollo, sin embargo, se completa a partir de las cualidades negativas de la escena: por un lado, no existe en el horizonte de representación criolla una meta tangible a alcanzar a pesar de su labor intelectual (no tienen a la vista el premio y eso los obliga a aflojar) y, más importante, Valdecebro acuña una frase que bien podría entenderse como un emblema de las quejas criollas a lo largo de este tiempo: la extrañeza en su propia patria. Utilizando de manera sutil un concepto de indiscutible carácter contradictorio (ser un extraño en su propia patria) Valdecebro tácitamente expresa dos ideas muy importantes que se ocupan de definir y delimitar el marco semántico de lo que llamo pose criolla. Si por un lado existe un claro sentido de pertenencia y posesión (su patria), simultáneamente se expresa un desplazamiento sufrido por el colectivo criollo que no les permite habitar su propio espacio. Claro está, Valdecebro en ningún momento está proponiendo una vindicación de todos los habitantes del espacio mexicano, sino que su propuesta opera como un canal por donde circulan las imágenes que definirán el heterogéneo ideario criollo, un ideario del cual su voz también forma parte en el proceso de construcción, creando así la necesidad de entender la fundación discursiva de lo criollo a partir de una polifonía. Una vez que el religioso establece el marco escénico que constituye su momentáneo lugar de enunciación, comienza a establecer una serie de retratos de los ingenios ilustres que él ha conocido y que sustentan su tesis acerca de la situación criolla:

Hubo maestro de mi Religión que dictó a cinco amanuenses diferentes materias a un tiempo mismo. Muchacho de quince años, que se graduó de Doctor en ambas facultades en la universidad de México. Otro, que de diez y nueve se opuso a la Cátedra de Decreto, y leyó de repente. Otro, que también de repente leyó dos diferentes puntos de Teología, el uno en Verso Latino llenando la hora; siguiendo el común estilo de oposición en el otro. Un ciego desde su nacimiento que se ha opuesto a Cátedras de Filosofía muchas veces. Otros muchos hay de altísimos ingenios y prendas (1648, p. 22).

Valdecebro establece un número no menor de hazañas intelectuales llevadas a cabo por sus aliados criollos, configurando un linaje y así mismo una comunidad letrada que no tiene nada que envidiar al resto de los centros urbanos del imperio. Este colectivo de ingenios poblanos no distingue cargos, edades, problemas físicos ni posiciones eclesiásticas. Tampoco existen restricciones en torno a la materia que cada uno de ellos demuestran conocer: ya sea un anciano maestro en su cátedra o un joven que sobrepasa con sus capacidades intelectuales a sus pares, todos ellos constituyen la materia que mantiene unido al tejido letrado. A pesar de esta valoración hiperbólica de sus pares mexicanos, Valdecebro mantiene en silencio los nombres de estos claros ingenios poblanos, una pudorosa anonimia que, quizás, pueda entenderse debido a que las hazañas intelectuales mencionadas no se ven traducidas inmediatamente en mejoras en la posición que estos sujetos ocupan en la ciudad barroca virreinal. Nuevamente, se pone en escena lo que podría llamarse una ambivalente vindicación del fracaso, ya que aquellos destacados letrados consumen su capacidad intelectual sin alcanzar el debido reconocimiento que merecen. Hablando específicamente de las cualidades de los criollos para la predicación, Valdecebro confirma la idea anterior al expresar que si bien "tienen para oradores el natural abierto y desenfadado; son prestos en el decir, vivos al ejecutar los discursos", sin embargo, "tan floridos ingenios se pasan en flor, porque no alcanzan al fruto del premio" (1648, p. 22). Sintetizando, las palabras de Valdecebro funcionan como una caja de resonancias donde los ecos de los ingenios criollos aún pueden escucharse, lamentando el estado de excepción en el que se encuentran, pero, simultáneamente, estableciendo que es el ingenio que detentan la señal de distinción que los hará partícipes del discurso imperial y que los diferenciará del resto de los habitantes del heterogéneo mundo virreinal americano. 


\section{Joseph Delgadillo y Sotomayor. Un HUmilde SERVIDOR PerUano}

El tercer texto que quiero mencionar en este recorrido de lectura se titula Arte de predicar preceptos de San Pedro Chrysologo sacados de sus Sermones fielmente escrito por el franciscano Joseph Delgadillo y Sotomayor. Este manual de predicación fue, como se deduce de la "Dedicatoria" que precede al tratado, compuesto en Cusco alrededor del año de 1674, y posteriormente enviado para ser impreso en Lima, donde aparece en 1676. Pocos datos se tienen de la vida y las obras de Delgadillo y Sotomayor. Investigando los textos preliminares a su Arte de predicar se puede aseverar que el padre Joseph era "hijo de la provincia de San Antonio de los Charcas" (Delgadilloy Sotomayor, 1676) y que tuvo una muy buena relación con diferentes figuras relevantes de la cultura virreinal peruana. El manual de oratoria está dedicado al franciscano y comisario general de la orden en Perú, el padre Alonso Garrido Melgar, religioso peninsular que había sido padre y custodio perpetuo de la provincia de Andalucía y a quién Delgadillo y Sotomayor dice entregar el libro como prenda de devoción ante su llegada a la provincia de Charcas para tomar el cargo eclesiástico. Este texto preliminar contiene toda una serie de elogios que, si bien parecen destacar la tarea pastoral y la autoridad de Garrido Melgar a partir de la analogía con diferentes figuras de poder de la antigüedad clásica grecolatina, simultáneamente, el tratadista peruano utiliza esta retórica del elogio ya que, afirma, "amparo seguro tengo dedicando aquesta obra a vuestra merced, luego que pone el pie en esta su provincia” (1676, p. XX). Como se podrá ver más adelante, este modo discursivo utilizado por Delgadillo y Sotomayor reaparece a lo largo de todo el tratado y define lo que se podría llamar su propia pose o figuración discursiva frente a la autoridad peninsular: el predicador peruano será solamente un canal, un mero transmisor del saber europeo. En el acto mismo de escribir un manual de predicación siguiendo las directivas tradicionales codificadas desde la publicación del famoso tratado de Fray Luis de Granada, Delgadillo y Sotomayor establece un marco de referencia específico y fácilmente reconocible por sus pares, los que podrán interpretar estos signos y así elaborar un sentido de pertenencia a un sector social a partir de una actividad intelectual reconocible.

La estructura del tratado, como anticipé, sigue muy de cerca las formas más utilizadas al momento de diseñar un arte de predicación. En las treinta y dos secciones del tratado se definen las características personales que todo predicador debe poseer, las diferentes clases de sermones, los tipos y los modos disímiles del estilo, las fuentes y los autores más importantes para el aprendizaje retórico, como así también las definiciones tradicionales de los tropos y figuras junto con toda una muy importante sección reflexionando sobre los vicios y virtudes de la acción y la pronunciación del sermón. Dentro de esta compleja superficie textual, resulta de singular importancia su definición del rol que él está cumpliendo al escribir un tratado desde el territorio virreinal. Esta función se puede observar se manera específica en la sección "Al Lector" incluida en los preliminares al texto propiamente dicho del tratado. En esta parte, Delgadillo y Sotomayor intenta demostrar la necesidad de un manual como el suyo en este particular espacio enunciativo debido a la falta de calidad de los tratados circulantes. Escribe el franciscano:

He visto multiplicarse los Artes de Predicar, y como aquestos preceptos de varios Maestros no son doctrina consiguiente, deseé un método seguido de un Doctor, y hallé que $S$. Chrysologo era y daba preceptos para todo, y como están esparcidos en todos sus Sermones los recogí cuidadoso; citando con fidelidad el lugar donde lo dice. Esto es el Arte (1676, p. 26).

Curiosamente, a diferencia de muchos otros letrados del nuevo continente, Delgadillo y Sotomayor no utiliza la idea de la carencia o la falta como imagen directriz de su intervención en los bordes de la ciudad letrada, sino que es la multiplicación (sin orden, sin clasificación y sin la debida calidad) lo que ha hecho posible y extremadamente necesaria su composición del tratado. Ahora bien, esta primera estrategia discursiva que pone el énfasis en su propia capacidad como sujeto que posee el ingenio necesario para corregir un problema que ha detectado en su campo cultural y así distinguirse por encima de muchos otros (tanto peninsulares como americanos) va a complejizarse a partir de una complicada torsión retórica propia de un discurso criollo que opera en sus palabras de forma subterránea y rizomática. El peruano asevera que él no ha 
hecho más que compilar lo que ya estaba ahí y era conocido por todos, pero que necesitaba el simple aliño y la clara ordenación que su tratado propone. Al definir a su manual enfáticamente observa que:

En él te enseña el Maestro cuanto quisieres saber. No me califiques a mí de que te quiero enseñar: que S. Chrysologo es el Maestro en este breve tratado. Y puesto lo sabes que está entre todos aplaudido, reconoce el modo que tuvo de disponer sus Sermones. Perdóname a mí el trabajo, que te aseguro que mis intentos han sido que tengas pauta y modelo para que prediques tú. Aquí verás tropos, y figuras ejercitadas en el Santo. Ya tienes muy gran Maestro, con cuya dirección puedes discurrir seguro. Lo que te suplico es que me perdones a mí los yerros de la disposición que es sólo lo que yo he puesto (1676, p. 27).

La figura autoral aparece aquí debilitada y definida sólo como un individuo que recoge la palabra del otro sabio y la ordena para dar una mejor coherencia y estructura. Lo que Delgadillo dice presentar es un compendio de reglas sacadas de los sermones de su maestro y reordenadas para que el lector "tenga pauta y modelo" para su futura predicación. El maestro, entonces, es el otro, la autoridad del pasado, que atraviesa el tiempo y el espacio y aún puede influir en aquellos que están esparcidos en los espacios más alejados del centro imperial. Delgadillo y Sotomayor será de esta manera solo un humilde servidor peruano que ha empleado su tiempo, su caudal y su ingenio para re-descubrir aquellos saberes que parecían estar dormidos en las letras del maestro.

\section{Martín de Velasco. El Criollo y SUS alianzas}

A finales de 1676, un sacerdote franciscano de cincuenta y seis años, nacido y criado en Santa Fe de Bogotá, en Nueva Granada, entrega a la imprenta un manuscrito titulado Arte de sermones para hacerlos y predicarlos por el R. Padre Predicador Fray Martín de Velasco. Casi un año después, el libro será publicado en Cádiz por Bartolomé Núñez de Castro. Si bien el Arte de sermones no es hoy ampliamente conocido, fue un texto de lectura asidua durante el período colonial. Su circulación en los territorios americanos está documentada a través de copias manuscritas, refundiciones y, por último, una reimpresión hecha en México cincuenta años después de la primera edición española, hechos que afirman su popularidad, carácter modélico y representatividad (Osorio, 1989, pp. 160-166).

Las veintinueve secciones del Arte comienzan definiendo el sermón como "un todo artificioso, que la Retórica Cristiana dispone para persuadir a las virtudes, y aborrecimiento de los vicios, pena, y gloria con brevedad de palabras. La dificultad no nace de que sea todo, ni retórico, ni Cristiano, sino de que sea artificioso" (Velasco, 1677, pp. 19-20). Esta primera cláusula señala el camino que se seguirá en este manual, ya que a lo largo de los apartados será posible notar una constante apelación a la idea de la práctica y el ejercicio como claves en la composición y predicación de los sermones. Desde un punto de vista retórico, se observan en el Arte ecos de polémicas presentes durante la cultura del Barroco en torno a la estructura y la funcionalidad del sermón. Me refiero a la constante tensión entre los tratadistas que defienden el estilo sublime y cargado de ornato, por una parte, y quienes exigen un lenguaje distanciado del poético y de la declamación teatral, por otra. El letrado bogotano demuestra fidelidad a esta última corriente, ya que en su libro propone mantener en un mínimo la complejidad lingüística de la superficie retórica del sermón, en pos de una mayor simpleza y claridad del mensaje a transmitir (p. 13). La "fábrica del sermón” (p. 20), como a Velasco le agrada llamar a su tarea, conlleva un número amplio de saberes y prácticas que deben ejercitarse para complementar las dotes naturales del sujeto que desea adquirir este arte. El aprendiz de este método debe comprender la necesidad de crear un balance entre lo doctrinal y lo artístico en busca del tan ansiado efecto en su auditorio. Para eso, expresa Velasco, se necesita pensar la oratoria como un todo coherente hecho de partes distintas y por momentos casi antagónicas que, sin embargo, bajo la experta mirada del predicador, mantienen una visible armonía, de la misma manera en que pensamos los distintos mecanismos que componen un reloj: “¿Qué importa que todas las piezas de un Reloj sean de por sí todas pulidas, limadas, y bruñidas, si en tus manos las 
tienes, y no sabes ajustarlas a sus lugares, poniendo la Campana en lugar de las Ruedas? (p. 20, mayúsculas en el original).

El libro presenta una estructura argumental similar a la de muchos otros manuales de oratoria. Los primeros capítulos (del I al III) se detienen en analizar la función de la oratoria y destacan las características del sermón en tanto composición retórica que busca la persuasión de su auditorio. Una vez explicado esto último, prestando especial atención tanto a la dimensión textual como a la doctrinal, Velasco continúa proponiendo los elementos que constituyen el sermón (las llamadas partes esenciales, integrales y materiales) y establece además que este debe cumplir, de acuerdo con la antigua retórica, con tres requisitos: ser fundado (el fundamento de la oración), lucido (la exornación, los tropos y figuras) y provechoso (pp. 21-25). Estas primeras caracterizaciones de la estructura textual del sermón dan paso a otras reflexiones sobre elementos tales como la pronunciación, el tono de la voz, los efectos sonoros desde el púlpito (pp. 45-46) y su conexión con el objetivo de la prédica, para llegar a la tradicional clasificación de los distintos estilos empleados en sus tiempos (el remiso, el blando y el magnílocuo), que para Velasco se presentan como opciones estilísticas que es posible combinar dentro de un mismo sermón, siempre y cuando no se confundan sus lugares (p. 47). Señala asimismo que el predicador debe prestar extrema atención a los movimientos del cuerpo en el púlpito, y, sobre todo, a los gestos realizados con las manos (pp. 87-90). El semblante, por ejemplo, debe estar en plena armonía con el entorno donde se predica y el auditorio al cual el predicador se enfrenta, para no desentonar con el objetivo final de la oración (p. 88). Enseñar, deleitar y mover al auditorio son los ejes conceptuales que organizan el tratado.

Uno de los aspectos más relevantes del texto de Velasco es el constante interés por reflexionar tanto sobre las cualidades retóricas del sermón como también en torno a la construcción del sujeto que deberá emplearlas. En las páginas del manual no vamos a encontrar un nuevo modo de predicación, sino una síntesis de obras previas, tanto del humanismo renacentista como de la contemporaneidad del autor. Lo que sí vamos a hallar, entonces, es una serie de reflexiones sobre el propio lugar de enunciación diferencial y la relación entre esta alteridad geográfica y la metrópolis. Esta inclusión del estatus del predicador criollo en las Indias va a presentarse en tres instancias textuales específicas que vinculan la idea de saber, práctica y lugar de enunciación. La primera mención se da cuando Velasco discute en la sección VII los diferentes estilos de la oratoria, junto con los vicios que muchas veces están presentes en esta y la necesidad de corregirlos. Allí el autor introduce una referencia a un predicador criollo como ejemplo acabado de aprendizaje y enseñanza del arte oratoria:

Débense conocer estos malos estilos para evitarlos, procurando obrar con perfección en los otros, como lo hizo en nuestros tiempos en la ciudad de Tunja, tan conocida por su nobleza como por los ingenios que produce, el Fénix de ellos y mayor talento de su siglo, el Bachiller Pedro de Barajas, cura doctrinero de Soraká (pp. 62-63).

La mención de Pedro de Barajas tiene un significado importante, ya que así no solo se incluye dentro del manual una referencia a la formación material del predicador (el estilo) sino que además se establece una conexión con las coordenadas témporo-espaciales (el presente, Tunja) que contextualizan el discurso producido por Velasco. Es Barajas un ejemplo del predicador criollo que refuerza la idea misma del Arte de Velasco como formador de subjetividades que habitan y practican la oratoria desde un espacio alternativo. La segunda mención a la actuación de los predicadores criollos aparece en la sección XVII del Arte, donde se recrea una discusión en torno al estilo y la finalidad persuasiva del sermón. Específicamente, Velasco afirma la necesidad de elaborar con mayor artificiosidad retórica los finales de los sermones y de evitar un cierre breve o casi trunco (pp. 134-35). Para Velasco "en esto fue insigne el Doctor Don Juan González, Cura Rector de esta Catedral de Santa Fe, bastantemente conocido en todo el Nuevo Reino, por sus letras, virtud y talentos" (p. 134). Resulta claro que la mención de estos dos predicadores busca destacar la idea de construcción de una comunidad letrada con intereses y localizaciones afines. No es casual que Velasco dé como ejemplos de grandes predicadores a dos letrados americanos que representan todo el espectro cultural 
que la oratoria barroca abarca: desde el cura doctrinero (Barajas) hasta el rector de la catedral de Santa Fe de Bogotá (González), todos forman parte de un heterogéneo colectivo que pugna por insertar sus intereses situacionales dentro del marco de la discusión y reflexión en torno a la predicación. Barajas y González son dos figuraciones ejemplares de la funcionalidad del predicador criollo que Velasco defiende y busca construir desde su propio texto.

Pero probablemente el ejemplo que mejor explique la compleja situación enunciativa de Velasco se halle en el apartado "Al lector", donde el bogotano dirige la palabra a un imaginario receptor de su obra. En esta sección se encuentran referencias explícitas a su condición de letrado indiano y además se presenta un tipo de queja reivindicatoria afín a lo expresado por diferentes autores criollos del siglo XVII. En este paratexto, Velasco busca establecer un vínculo preciso entre el saber, el espacio de enunciación y el deseo de reivindicar a su propia comunidad intelectual criolla. Dialogando con su lector, reafirma la necesidad de escribir otro arte de sermones a finales del siglo XVII:

Dirás que en esta materia hay muchos Artes, y que el mío se vuelva, pues viene tarde. A que respondo: Que muchos de ellos he leído, pero todos me dan licencia para que el mío se imprima (quizás será de algún provecho) y con licencia suya, y ruegos de mis amigos lo doy a la estampa, para dárselo impreso, por no poder trasladarlo para todos los que piden. (1677, pp. 9-10).

El retardo temporal aparece aquí transformado en algo positivo, ya que es el tiempo transcurrido lo que le permite al activo letrado criollo estudiar los distintos artes de sermones e incorporar en sus enseñanzas las experiencias de un nuevo sujeto social que ha tenido que lidiar con escenarios inexistentes cuando escribieron los tratadistas anteriores. Velasco se refiere en este párrafo a su contexto social americano en toda su complejidad: es consciente de su situación no privilegiada en el circuito de producción y circulación del saber, pero frente a ese marco de desventaja señala las singularidades que harían su tratado indispensable. El tratadista va construyendo así un individuo capaz de evaluar lo escrito anteriormente y concluir que es necesario (aún a finales del siglo XVII) imprimir un arte de sermones desde las márgenes del imperio, para poder crear un tipo de predicador afín a este territorio. Es debido a la suma de la experiencia individual, el conocimiento del archivo previo y la aprobación de un grupo social que se nombra difusamente (los anónimos "amigos" de la cita de Velasco) por lo que el libro reclama su espacio en el mapa cultural. Los libros del pasado, leídos, interpretados y estudiados con detenimiento por este letrado criollo, dan licencia al nuevo predicador, mientras que el grupo social al que pertenece y con el que siente afinidad opera como el factor que permite la concreción del libro, abandonando el espacio privado del claustro y haciéndose visible al público de la ciudad barroca.

Siguiendo este razonamiento, Velasco comienza a expresar de manera más enfática y explícita su situación a través de una serie de quejas que buscan desestimar ciertos prejuicios peninsulares hacia la producción cultural criolla. En este caso, el bogotano continúa el diálogo con su lector, al que le pide que refrene su ánimo crítico y que tenga en cuenta el eje de enunciación del Arte:

Para este fin te ofrezco mi Arte. Lector, déjame pasar sin vejación, que una buena intención no es ropa de contrabando: si gustas de entretenerte, castiga en mí los vicios, que tendrás en ellos diversión para muchos días, pero mira, que esta que ofrezco, es virtud, no me la muerdas. Lo que hay en el Arte, que puede ser sea para ti de misterio, es que este libro se escribe En, y sale De (es mi obligación decirlo) Las Indias. Buscando en los Reinos de España, no el aplauso, sino la prensa, prevenido, y amonestado (1677, p. 15).

En primer lugar, Velasco establece el marco cultural preciso de producción del Arte a través de la creación y delimitación de un espacio enunciativo diferente. A su vez, el predicador establece que es necesario confesar esto ("es mi obligación decirlo") frente a un auditorio (el peninsular) que, según saben los criollos, descree de la capacidad intelectual de los nacidos en tierras americanas. La empresa que Velasco, como letrado criollo, quiere llevar a cabo es doblemente riesgosa, ya que implica brindarle a la autoridad metropolitana la oportunidad de evaluar su libro negativamente y continuar con la serie de estereotipos que marginan al criollo. Este escenario riesgoso promueve en el criollo un sentimiento ambiguo, en la medida en que aquello 
que lo va a dar a conocer en el campo letrado (la publicación en España) lo expondrá al mal recibimiento por parte de los metropolitanos. Velasco describe esta situación de la siguiente manera:

Y es tanto el aborrecimiento, que algunos tienen a las Indias, que por maldecirlas se revisten, una y otra vez, de Fariseos. Y con los modernos (estos sí que les toca, y esta es la historia y la tecla) ¿sabes quiénes fueron? ¿No has oído aquello de los Comuneros? Pues estos fueron los Fariseos, que a un tiempo despedazaron a Castilla, y entablaron el aborrecimiento a las Indias. ¿Miren, qué dos cosas, y miren quiénes? Di ahora lo que quisieres, que no faltará quien te conozca, pues en lo que hablaste te manifiestas, y si quieres que no te descubran en Castilla, calla, no ladres hacia las Indias, que eso más es descubrir el corazón que desahogar el pecho (1677, p. 16).

Según Velasco, el hecho de "aborrecer" y "maldecir" a las Indias es un signo propio de aquellos que van en contra de la grandeza de la Monarquía española, no solo desde el orden político sino además en la dimensión religiosa, que incluye mediante la analogía fariseos/comuneros. En ese sentido, construye un mito de origen del descrédito hacia América basado en el levantamiento de los comuneros en contra de Carlos $\mathrm{V}$ y así une el afianzamiento del destino imperial español con la expansión ultramarina. A través de un certero razonamiento retórico, el predicador neogranadino invierte la valoración de los prejuicios contra los criollos, ya que en realidad son aquellos que los critican quienes se muestran como enemigos del orden monárquico señorial (son los herederos de los comuneros). De esta manera, lo que hace Velasco no es rechazar lo metropolitano, sino establecer un vínculo entre la colonia y la metrópolis que se funda en una mitología compartida: Castilla y los criollos se enfrentan a un mismo tipo de enemigo que desea ver la derrota de la casa Habsburgo.

Velasco negocia el espacio de enunciación criollo dentro de las redes del poder imperial, no a través de una oposición binaria, sino por medio del denominador común de la amenaza interna que puede contribuir a la ruina del status quo, reconociendo elementos intermedios tanto en los virreinatos como en la Península. Con su particular construcción de su lugar de enunciación, Velasco asume frente a la autoridad metropolitana un carácter ultraortodoxo que lo hace heredero y continuador de quienes sostuvieron el poder imperial desde sus inicios mismos, mientras que, ante sus pares indianos, sus palabras resuenan como una defensa apologética del sector criollo. Justamente eso hará hacia el final de la sección, donde el criollo decide incluir la referencia a su naturaleza de autor y su alteridad geográfica como otro de los elementos que irían en detrimento de su creación ante los ojos de los "comuneros":

Por no leer los comuneros un libro escrito en Las Indias, no quisieran que hubiese ingenios en las Indias. Si a ellos dirigiera yo el mío, no me faltará artificio para esconder la Patria, y el nombre de Las Indias, que tanto los ofende; pero siendo pragmática tan justa, que el libro salga con el nombre, y Patria de su dueño, hágolo como se manda, logrando en esta obediencia, un artificio para mí de mucho provecho (pp. 16-17).

En primer lugar, la presencia del nombre propio funciona aquí como una sinécdoque del grupo criollo que se ha adueñado del derecho a representar el significante "Indias". En segundo lugar, se vuelve a destacar el grado de desarrollo intelectual americano al demostrar que un autor nacido en el Nuevo Mundo ha escrito un tratado de oratoria sagrada que será impreso en la metrópolis y que desmiente el deseo de aquellos que desprecian a América ("no quisieran que hubiese ingenios en las Indias"). A su vez, el uso del nombre propio es también una señal dual de la obediencia de este sector ("hágolo como se manda") hacia las autoridades y del orgullo de su procedencia, algo que Velasco define como "un artificio para mí de mucho provecho".

Como puede deducirse de los fragmentos analizados, Velasco reflexiona sobre su espacio de enunciación y las relaciones con el discurso peninsular creando un marco narrativo que le permite incluir, simultáneamente, crítica y fidelidad hacia sus pares españoles. Esta ambivalencia discursiva implica proponer la necesidad de la figura del predicador criollo como un rol que ha sido y será, gracias al Arte de sermones, de extrema importancia en el mundo barroco. Sus quejas pretenden desagraviar a los creadores criollos por medio de la escritura misma de un volumen que será prueba cabal de la capacidad intelectual de estos, sin romper de manera radical con el orden imperial. En la introducción a esta sección, destaqué la necesidad de revisar el texto de Velasco 
como exponente cabal de la intersección cultural entre el discurso barroco y el grupo criollo, buscando aquellos elementos que participan en la construcción de una figura de autoridad intelectual creada a partir del uso de lo que llamo la organización discursiva del tiempo, del espacio y de los vínculos con los otros. La creación de esta pose criolla se basa en la ubicación del letrado criollo como intermediario entre cosmovisiones contrapuestas, es decir, que sostiene su identidad en tanto es la autoridad intelectual que se encuentra en un lugar privilegiado para relacionarse tanto con los agentes del poder metropolitano como con el heterogéneo tejido social americano. Por momentos, Velasco asumirá en su palabra un espacio geográfico alternativo vinculado indudablemente con la realidad austral; pero también, en ocasiones, su deseo de participar de la cultura europea lo llevará a buscar tropos que conecten estos dos espacios sin ir en detrimento de ninguna de las coordenadas locativas. Esto le permitirá ubicarse siempre en un espacio epistemológico privilegiado: frente a los peninsulares, asumirá el rol del sujeto nativo que, debido a su origen geográfico, posee el conocimiento necesario para administrar su espacio; frente a sus pares criollos, usará una figuración discursiva que busca contribuir a un afianzamiento social y cultural del grupo.

En definitiva, Velasco construye su imagen de letrado criollo como sustento y base de su autoridad cultural, autoridad que oscila entre la aceptación de la jerarquía y el orden imperiales y la progresiva conformación de un lugar enunciativo distinto, en constante construcción, que transita zonas culturales diversas. Este nuevo lugar de enunciación no representa en su totalidad el espacio americano, sino que afirma y sustenta el dominio del grupo criollo ante la heterogeneidad del "Nuevo Mundo". Es posible ver en este ejemplo del discurso criollo del siglo XVII cómo este sector se apropia por momentos del significante "americano" y le impone una significación suplementaria, creando un efecto retórico que utiliza una falsa relación sinonímica entre dos palabras (criollo/americano) cuando dirige su discurso a la autoridad peninsular, mientras no duda un instante en trazar las diferencias entre los dos significantes cuando debe demarcar su dominio territorial y cultural dentro de la ciudad barroca americana.

\section{Conclusiones}

Esto cuatro casos que he muy brevemente analizado muy brevemente permiten ver que el proceso de construcción de lo que he dado en llamar el predicador criollo no puede solamente ubicarse en un espacio y un tiempo determinados, ni tampoco debería pensarse como una construcción discursiva homogénea y sin tensiones aparentes. Prefiero pensar este proceso como una multiplicidad de voces donde se van articulando los diferentes idiolectos que forman parte del discurso criollo; un discurso que si bien ya sabemos no puede interpretarse de forma simplista, ingenua y superficial asignándole un valor representativo de lo americano (visión contra-hegemónica, de la ideología criolla) tampoco parece adecuado asignarle una teleología clara, definida, sin fisuras y forjada por una sólida elite letrada que busca denodadamente hacerse dueña de un horizonte de significación preciso. Estas cuatro formas de crear un predicador desde América pueden entenderse mejor como una operación polifónica, como un proyecto coral y heterotópico, en permanente proceso de configuración a lo largo de todo el siglo XVII.

\section{REFERENCIAS}

Cerdan, F. (1985). Historia de la historia de la Oratoria Sagrada española en el Siglo de Oro, Introducción crítica y bibliografía. Criticón, 32, 55-107.

Cerdan, F. (2002). Actualidad de los estudios sobre oratoria sagrada del Siglo de Oro (1985-2002): Balance y perspectivas. Criticón, 84-85, 9-42.

De la Flor, F. R. (1995). La oratoria sagrada del Siglo de Oro y el dominio corporal. En Culturas en la Edad de Oro (pp. 123-147). Madrid: Editorial Complutense. 
Delgadillo y Sotomayor, J. (1676). Arte de predicar preceptos de San Pedro Chrysologo sacados de sus Sermones fielmente. Lima [s.n.]

Ferrer de Valdecebro, A. (1658). El orador católico, atento y advertido. Aviso y persuasión a los neothericos oradores. Madrid: Diego Díaz de la Carrera.

Granada, L. de (2010). Los seis libros de la retórica eclesiástica, o método de predicar. Logroño: Instituto de Estudios Riojanos.

Herrero Salgado, F. (1986). La oratoria sagrada en los siglos XVI y XVII. Madrid: Fundación Universitaria Española.

Osorio Romero, I. (1989). Conquistar el eco: la paradoja de la conciencia criolla. México, DF: UNAM.

Quetif, J. y Jacques Echard (1719). Scriptores Ordinis Praedicatorum Recensiti, Notisque Historiciset Criticis Illustrati. Tomus Secundus. Paris: Ballard et Simart.

Roig Condomina, V. (1989). Las empresas vivas de Fray Andrés Ferrer de Valdecebro. Valencia: Imprenta Llorens.

Rodríguez de León, J. (1638). El predicador de las gentes San Pablo. Ciencia, preceptos, avisos y obligaciones de los predicadores con doctrina del apóstol. Madrid: María de Quiñones.

Smith, H. D. (1978). Preaching in the Spanish Golden Age: A Study of Some Preachers of the Reign of Philip III. UK: Oxford UP.

Torre Villar, E. de la (1996). El humanista Juan Rodríguez de León Pinelo. México: UNAM.

Velasco, M. de (1677). Arte de sermones para saber hacerlos y predicarlos dedicado al fray Iván de Herrera, lector de prima yprior del convento de predicadores de la ciudad de Cartagena y vicario provincial de todos los de la costa de Cartagena y Santa Marta. Cádiz: Bartolomé Núñez de Castro.

\section{Notas}

1 El testimonio de esto es la "Licencia de orden" que aparece en el Orador católico, firmada en 1644 por Fray Diego González, calificador del Santo Oficio, catedrático de Prima de la Universidad de México y prior de la provincia de Santiago de la Nueva España.

2 De los catálogos consultados (Quetif, Anotnio, Latassa, Median y Durán) se deduce una gran producción intelectual durante su período en Puebla, con obras escritas que van desde los años de 1650 hasta 1658. Los temas de ellas son diversos, si bien hay una clara línea religiosa en sus producciones. Al día de hoy, no se han podido hallar los textos que Valdecebro escribió en Nueva España a excepción del Orador católico.

3 Vicente Roig Condomina en su estudio Las empresas vivas de fray Andrés de Valdecebro (1989, pp. 11-24) presenta un excelente resumen de la vida y las obras del predicador dominico.

4 Su sobrino Ausías Antonio Ferrer de Valdecebro escribe un breve texto introductorio a la obra El templo de la fama (publicada en 1680 luego de la muerte del letrado aragonés) donde afirma que a su tío "le desterraron de la Corte por un libro que dijeron había escrito contra los médicos llamado El Nigromántico” (Roig Condomina, 1989, p. 12). 